\title{
Increased epithelial cell proliferation in the ileal pouch mucosa of patients with familial adenomatous polyposis
}

\author{
P. Friederich • B. W. H. van Heumen • I. D. Nagtegaal • \\ M. Berkhout • J. H. J. M. van Krieken • \\ W. H. M. Peters $\cdot$ F. M. Nagengast
}

Received: 25 February 2007 /Revised: 2 June 2007 / Accepted: 13 June 2007 / Published online: 5 July 2007

(C) Springer-Verlag 2007

\begin{abstract}
To eliminate the risk of colorectal cancer in patients with familial adenomatous polyposis (FAP), reconstructive proctocolectomy is performed. Although most colonic mucosa is resected during the ileal pouch anal anastomosis, adenomas and carcinomas may develop in the pouch. This may be caused by altered cell kinetics due to intraluminal changes in the pouch. In 32 patients with FAP, biopsy specimens from the mucosa of the pouch and also of the afferent ileal loop were taken. Tissue sections were immunohistochemically processed with the monoclonal antibodies M30 and MIB-1 to assess apoptotic and proliferative indices, respectively. Cell proliferation was also assessed by a modified sign test. There were no significant differences in apoptotic rates between the mucosa of the pouch and the mucosa of the afferent ileal loop. However, cell proliferation was significantly higher in the mucosa of the pouch vs afferent ileal loop, both by using the quantitative $(68.3 \%$ vs $61.6 \%, p=0.001)$ and semiquantitative methods $(p<0.05)$. Our newly developed semiquantitative approach outperformed previously described methods. The higher cell proliferation in the pouch as compared to the afferent ileal loop may contribute to the
\end{abstract}

The experiments performed for this study comply with the current laws of The Netherlands.

P. Friederich $(\bowtie) \cdot$ B. W. H. van Heumen · M. Berkhout

W. H. M. Peters $\cdot$ F. M. Nagengast

Department of Gastrointestinal and Liver Diseases,

Radboud University Nijmegen Medical Centre,

P.O. Box 9101, 6500 HB Nijmegen, The Netherlands

e-mail: Friederich@tiscali.nl

I. D. Nagtegaal • J. H. J. M. van Krieken Department of Pathology,

Radboud University Nijmegen Medical Centre,

Nijmegen, The Netherlands increased risk for adenomas and carcinomas in the pouch of patients with FAP and emphasizes the need for regular endoscopic surveillance.

Keywords Familial adenomatous polyposis $\cdot$ Restorative proctocolectomy $\cdot$ Cell proliferation $\cdot$ Apoptosis and carcinogenesis

\section{Introduction}

Familial adenomatous polyposis (FAP) is an autosomaldominant disease with an estimated prevalence of 1 in 5,000 to 1 in 7,500 [5]. It is characterized by the development of hundreds of adenomas in the large intestine. Without surgical intervention, virtually all patients will develop colorectal cancer at relatively young age.

To eliminate the risk of colorectal cancer, a restorative proctocolectomy with ileal pouch anal anastomosis (IPAA) is accepted as one of the surgical treatments of choice in these patients.

In the IPAA procedure, almost all colonic mucosa is resected, thus reducing cancer risk significantly. However in patients with FAP, adenomas are also present in the upper gastrointestinal tract; approximately $5 \%$ of the patients having gastric, 60 to $90 \%$ duodenal [4], 50\% jejunal [14], and 9 to $25 \%$ ileal adenomas $[14,23,34]$. Occurrence of ileal adenomas is of special interest because the terminal ileum, which is used to construct the pouch, may already contain adenomas. There is accumulating evidence that adenomas develop in the pouch. The reported incidence after a follow-up of at least 5 years is 8 to $60 \%$, increasing up to $75 \%$ in certain subgroups $[14,26,33,38]$, which is much higher as 
compared to the reported incidence of $9-25 \%$ in the preoperative ileum of patients with FAP [14, 23, 34]. Therefore, it seems that in the ileal pouch of patients with FAP, the development of adenomas is accelerated. At present, the malignant potential of the pouch adenomas is unclear. However, 13 patients with a carcinoma in the pouch have been recently described in the literature $[2,3$, 7, 9, 13, 24, 25, 29, 35-37].

Stasis in the pouch causes a change in the luminal content, which is in close contact with the ileal mucosa. There is an increase in the concentration of short-chain fatty acids to colonic levels [10], an increase in anaerobic bacterial counts resulting in a more colonic type of flora, and an increased deconjugation and dehydroxylation of bile acids by anaerobic bacteria [20,21]. The intestinal flora could play a role in initiation and promotion of colon cancer by activation of various classes of carcinogens, such as nitrosamines, polycyclic aromatic hydrocarbons, and glycosides [17]. A direct link between intestinal bacterial flora and tumor promotion in the $\mathrm{APC}^{\mathrm{Min} /+}$ mouse model for FAP has already been established [22].

Therefore, we hypothesize that the intraluminal ecological changes in the pouch are responsible for enhanced tumor formation in the mucosa of the pouch. Alteration of cell kinetics in the mucosa, including a lower rate of apoptosis and a higher rate of cell proliferation, is associated with tumor initiation and promotion. In colorectal cancer, the balance between apoptosis, cell proliferation, and cell shedding is disturbed, and such changes may favor the development of adenomas [30]. Up to now, no data are available on changes in proliferation and apoptosis rates of the ileal mucosa of the pouch after IPAA in patients with FAP.

The aim of this study is to investigate changes in apoptosis and cell proliferation rates, occurring in the mucosa of the pouch of patients with FAP, in comparison with the ileum of the afferent loop. The results may contribute to a better understanding of the enhanced adenoma formation in the pouch compared to normal ileum.

\section{Materials and methods}

Patients and tissues

The study was approved by the regional medical ethical commission, and informed consent was obtained from all patients.

Patients with FAP and an IPAA, who were under surveillance in the Radboud University Nijmegen Medical Centre or regional affiliated hospitals, were invited to participate in this study. Thirty-two patients with FAP were included. The diagnosis FAP was based on either a clinical presentation of at least 100 colonic adenomas or a mutation in the APC gene. Data concerning the surgical procedures were obtained from medical records.

From each patient, mucosal biopsy specimens of both the pouch and the afferent ileal loop were obtained during a regular surveillance endoscopy, in the period January 2002 until April 2004. Patients were fasted overnight. On the day of examination, patients were encouraged to drink liberally. No laxatives or cathartic enemas were given. To clear the pouch of fecal ruminants, two $250-\mathrm{ml}$ water enemas were given before the endoscopy.

The endoscopy was performed with an Olympus GIF$1 T 140$ video endoscope. From January 2002 until August 2003, a 2.8-mm diameter biopsy forceps (FB 13K-1 Olympus, Tokyo, Japan) was used, and from September 2003 until April 2004, a 3.0-mm diameter biopsy forceps (B102-C1-30.160 MedWork/Treier Endoscopie GA, Beromünster, Switzerland) was used. The afferent loop was introduced up to $20 \mathrm{~cm}$ proximal of the pouch. The mucosa was sprayed with $1 \%$ indigo carmine dye (Laboratoires SERB, Paris) at 1:1 dilution with water, where after photographs were taken to evaluate number and size of adenomas present.

For pathological examination, at least four biopsies were taken at random locations from the afferent ileal loop (10 to $20 \mathrm{~cm}$ proximal from the pouch), four biopsies from the pouch mucosa (at least $5 \mathrm{~cm}$ proximal from the anal verge), and four biopsies from adenomas if present. The biopsies from adenomas were used only for pathological evaluation, i.e., to exclude serious dysplasia in pouch adenomas, and were not used for research purposes. The biopsies were stretched on filter paper to maintain correct orientation of crypts, fixated in formalin, and embedded in paraffin.

Immunohistochemistry

Cell proliferation and apoptosis were measured in the stretched formalin-fixed nonadenomatous tissue. The crypt cell proliferation activity was assessed after staining with the monoclonal antibody MIB-1 (Dako A/S, Glostrup, Denmark), which recognizes the Ki-67 nuclear antigen of dividing cells in formalin-fixed paraffin-embedded tissue [8]. Apoptosis was assessed by staining with the monoclonal antibody M30 (Roche Diagnostics, Mannheim, Germany), which recognizes cleaved cytokeratin 18 . Immunoreactivity of M30 is confined to the cytoplasm of apoptotic epithelial cells and is expressed during early apoptosis [18].

Tissue sections of 4- $\mu \mathrm{m}$ thickness were cut from paraffin blocks, mounted on electrostatic slides (Super Frost Plus, Menzel-Gläser, Germany), and dried overnight, followed by drying in a stove at $50^{\circ} \mathrm{C}$ for $15 \mathrm{~min}$. 
Sections were put in xylol for $10 \mathrm{~min}$ and taken from xylol through $100 \%$ alcohol to water. After deparaffinization, endogenous peroxidase was blocked by treatment with $3 \%$ hydrogen peroxide in phosphate-buffered saline (PBS) for $30 \mathrm{~min}$. Pretreatment was performed by heating the tissue sections in citrate buffer $(10 \mathrm{mmol} / \mathrm{l}, \mathrm{pH} 6.0)$ at 180 $\mathrm{W}$ power in a microwave oven for $10 \mathrm{~min}$. After cooling at room temperature for $1.5 \mathrm{~h}$, sections were rinsed with PBS. Then, 20\% normal horse serum (Vector Laboratories, Burlingame, CA, USA) was applied for $10 \mathrm{~min}$. The sections were then incubated overnight at $4^{\circ} \mathrm{C}$ with either the mouse monoclonal antibodies MIB-1 at 1:1,000 dilution or M30 at 1:100 dilution.

Thereafter, the sections were rinsed in PBS for $10 \mathrm{~min}$ and incubated with biotinylated horse anti-mouse $\operatorname{IgG}$ (Vector) for $30 \mathrm{~min}$. After rinsing for $10 \mathrm{~min}$ in PBS, incubation with 'avidin and biotinylated horseradish peroxidase macromolecular complex' (Vector) was performed for $45 \mathrm{~min}$. Finally, $5 \mathrm{mg} / 10 \mathrm{ml}$ diaminobenzidine was used as chromogen, and the sections were put in $0.5 \% \mathrm{CuSO}_{4} / 0.9 \%$ $\mathrm{NaCl}$ for $5 \mathrm{~min}$ to intensify the staining. Mayer hematoxylin counterstaining was applied. Sections were dehydrated through $100 \%$ alcohol, cleared in xylol, and coverslipped with permount (Fisher Scientific, Fiar Lawn, NJ, USA).

Tissue sections of rectal carcinoma were used as positive controls.

\section{Evaluation of immunostaining results}

Investigators were blinded for the origin of the tissue sections, regarding patient and biopsy location.

For evaluation of M30 staining, tissue sections were examined by light microscopy. M30 positivity was identified as brown cytoplasmic staining. M30-positive cells were marked by a first investigator $(\mathrm{BvH})$ and reevaluated by an expert pathologist (IN). In all cases, the complete section was evaluated, and all M30-positive epithelial cells were counted. The apoptotic index was expressed as the number of M30-positive cells per tissue area in square millimeters. Tissue area was assessed by using a Zeiss KS400 computer-aided system.

In each MIB-1-immunostained tissue section, crypts whose entire length could be visualized were photographed under $\times 400$ magnification using a Zeiss KS400 computeraided system. Crypts were excluded when they did not reach the muscularis mucosae or had multilayered bases.

MIB-1 positivity was identified as brown nuclear staining. The number of MIB-1-positive epithelial cells and the total number of epithelial cells in up to five crypts per tissue section were counted from screen. The labeling index for each crypt was given by the ratio of MIB-1positive cells and the total number of crypt epithelial cells and is expressed as percentage of total. For each patient, the labeling indices of pouch and afferent ileal loop were expressed as means of three to five counted crypts. If less than three crypts could be photographed for either pouch or ileal loop, the patient was excluded from analysis. The photographed crypts of five randomly selected patients were counted twice by one investigator $(\mathrm{BvH})$ to determine intraobserver variability.

Although great effort was made to obtain well-orientated mucosal crypts when using the quantitative method, however, not all biopsies reached the criteria mentioned above, and therefore, could not be examined. This problem mainly occurred in the biopsies taken from the pouch and might be due to friability of the pouch mucosa. We therefore developed a new semiquantitative scoring system. A representative part of the biopsies showing several complete crypt/villous axes was photographed under $\times 100$ magnification. The photographs were judged pair-wise (pouch vs afferent loop) during which the investigators had to choose from four possible outcomes; one of the two locations showed most MIB-1 positivity. MIB-1 positivity did not differ or no judgement could be made. Judgement was based on relative length of the area of positive cells and the relative size of the stem cell compartment. Five investigators, two pathologists (IN, HvK), two gastroenterologists $(\mathrm{PF}, \mathrm{FN})$, and one junior investigator $(\mathrm{BvH})$ independently compared the paired photographs of biopsies of pouch and afferent ileal loop of all patients. When three or more observers agreed in their judgement, this judgement was denoted as consensus judgement. If this criterion was not met, no consensus was reached. If the quality of the tissue sections was poor, no judgment was made. One investigator $(\mathrm{BvH})$ judged the whole series twice for evaluation of intraobserver reliability.

\section{Statistical analyses}

Values for apoptosis and cell proliferation in the quantitative study were not expected to be normally distributed; therefore, they were presented as median and range. The Wilcoxon matched-pairs signed-ranks test was used to compare the paired observations in the apoptosis staining and the paired mean labeling indices in the cell proliferation study.

Consensus judgements on the semiquantitative assessment of cell proliferation, favoring either pouch or ileal afferent loop, were compared with a Sign test. To evaluate the reliability of this semiquantitative method to assess cell proliferation, Cohen's kappa was calculated for the first and second series of judgements by the prime investigator to determine intraobserver reliability. Also, for each pair of investigators, a Cohen's kappa was calculated. The mean Cohen's kappa was taken as value for interobserver reliability. 
Table 1 Patient characteristics

\begin{tabular}{lll}
\hline & Apoptosis & $\begin{array}{l}\text { Cell } \\
\text { proliferation }\end{array}$ \\
\hline Number of patients studied & 32 & 20 \\
Male/Female & $19 / 13$ & $12 / 8$ \\
Median age in years (range) & $32(16-72)$ & $29(16-62)$ \\
Median age at surgery in years (range) & $24(10-55)$ & $20(10-52)$ \\
Median age pouch in months (range) & $96(9-216)$ & $105(9-216)$ \\
IPAA: hand-sewn/double-stapled/ & $9 / 21 / 2$ & $5 / 14 / 1$ \\
unknown & & \\
Carcinoma at surgery & 4 & 0 \\
Patients with adenomas at biopsy: & $24 / 8$ & $15 / 5$ \\
yes/no & & \\
\end{tabular}

For quantitative cell proliferation analysis, 12 patients had to be excluded from analysis (right column) due to absence of sufficient evaluable crypts (see under "Materials and methods").

Consensus judgments were compared to the difference in mean labeling index between pouch and ileal afferent loop for each evaluable patient.

A $p$ value less than 0.05 was considered as significant (SPSS for Windows 11.0.1, 2001).

\section{Results}

\section{Patient characteristics}

Patient characteristics are given in Table 1 . The median age of the 32 patients (19 men, 13 women) included in the study was 32 (range 16-72) years.

Twenty-three patients were operated in the Radboud University Nijmegen Medical Centre. The median age at the time of reconstructive colectomy was 24 (range 10-55) years. A mucosectomy with hand-sewn IPAA was performed in 9 patients, and a double-stapled IPAA was performed in 21 patients. For two patients, the information about the performed technical procedure could not be retrieved. At the moment of colectomy, four patients had a colorectal adenocarcinoma localized in the rectum, sigmoid, hepatic flexure, or appendix, respectively.
At the time of endoscopy, the median age of the pouch was 96 (range 9-216) months. The medication used was loperamide by 18 patients, psyllium fibres by 3 patients, and iron, metoclopramide, colestyramine, omeprazole, sulindac, tramadol, tamoxifen, gosereline, nifedipine, metoprolol, furosemide, or losartan each by 1 patient. Thirteen patients were not on medication 3 months before endoscopy.

One patient used sulindac, a nonspecific cyclooxygenase inhibitor, which is thought to influence cell proliferation and especially apoptosis $[15,27]$. Exclusion of this patient from analyses had no effect on the results.

Histological examination revealed pouch adenomas in 24 patients $(75 \%)$.

\section{Apoptosis}

In both pouch and afferent ileal loop, M30-positive cells were predominantly detected in the mucosal villi (Fig. 1).

In the 32 pairs of biopsies from pouch and afferent ileal tissue investigated, the median absolute number of apoptotic cells in the pouch mucosa was two per tissue section (range 0-9), which was identical to the values in the afferent ileal loop (2, range 0-19). The median apoptotic index (expressed as number of M30-positive cells per $\mathrm{mm}^{2}$ tissue section area) did not differ between pouch (median $0.4 / \mathrm{mm}^{2}$, range $0-2.9$ ) and afferent ileal tissue (median 0.3 , range $0-2.7$; see Fig. 2).

\section{Cell proliferation}

\section{Quantitative comparison}

The intraobserver reliability for counting of the photographed crypts (Fig. 3) was $r_{\mathrm{s}}=0.855, p=0.002$.

In 12 pouch tissue sections, less than three crypts were available for counting, and these samples were therefore excluded from analysis. For the same reason, two afferent ileal tissue sections were excluded. In the 20 pairs of pouch and afferent ileum tissue sections left for comparison, median labeling index (expressed as percentage of MIB-1positive epithelial crypt cells) was significantly higher in

Fig. 1 Apoptotic epithelial cells (encircled) using M30 immunohistochemistry. Original magnification $\times 200($ left $)$ and $\times 400$ (right)
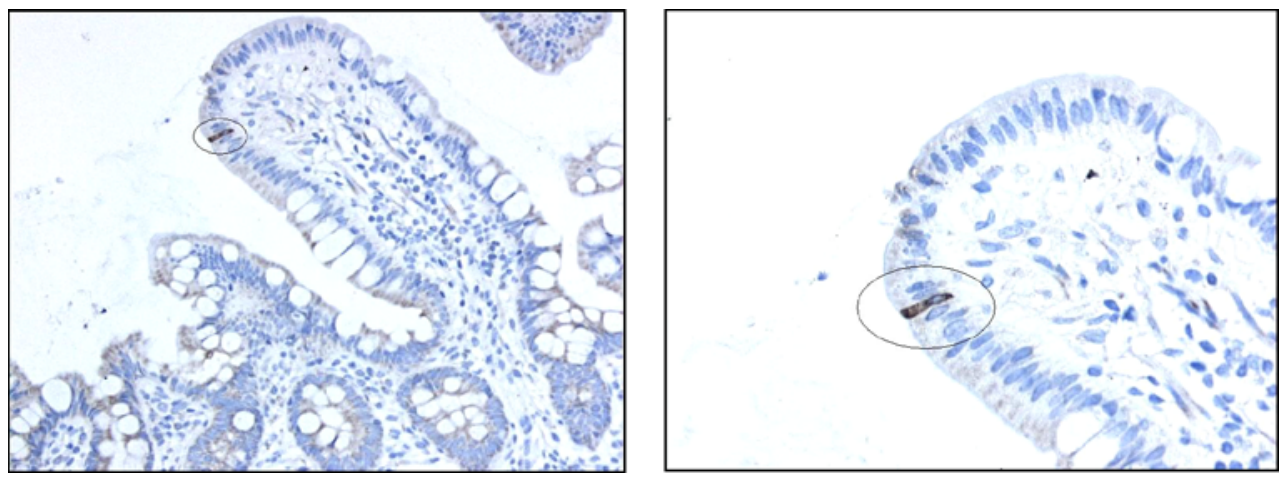


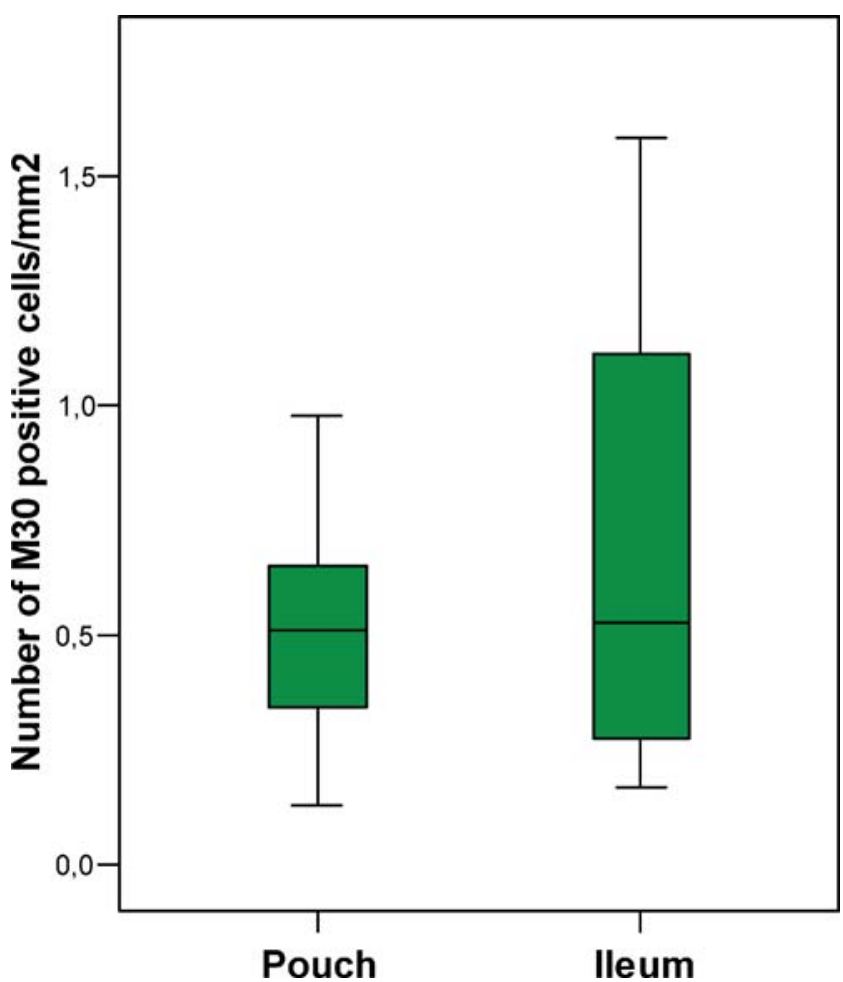

Fig. 2 Box-Whisker plots of apoptosis expressed as number of M30positive epithelial cells per $\mathrm{mm}^{2}$ tissue section area of pouch and afferent ileum of 32 patients with FAP. Difference between groups was not significant. Values are given as median (fat line), lower to upper quartile (green box), and minimum and maximum values (error bars)

the pouch as compared to the afferent ileum (median $68.3 \%$, range $52.9-79.6 \%$ vs median $61.6 \%$, range 38.0 $73.9 \%$; Wilcoxon signed-ranks test, $p=0.001$; Fig. 4).

\section{Semiquantitative comparison}

The results of the semiquantitative comparison of the photographed tissue sections from the pouch and afferent ileum mucosae (Fig. 5) are visualized in Fig. 6. In 15 patients (47\%), the proliferation was higher in the pouch; in 7 patients $(22 \%)$, there was no difference; in 5 patients $(16 \%)$, proliferation was higher in the afferent ileal loop; in 2 patients (6\%), no consensus could be achieved; and in 3 patients $(9 \%)$, no judgement was possible due to poor quality of the tissue sections. These differences were significant $(p<0.05)$.

Intraobserver reliability was $\kappa=0.87$. Cohen's kappa for each pair of observers ranged from 0.26 to 0.59 with a mean Cohen's kappa of 0.38 , which corresponds with "fair agreement" following Byrt's guidelines [6]. Thus, interobserver reliability was acceptable.

In cases in which a labeling index could be assigned to both pouch and afferent ileal loop, consensus judgment was available in 18 cases (Fig. 7). In all cases in which the

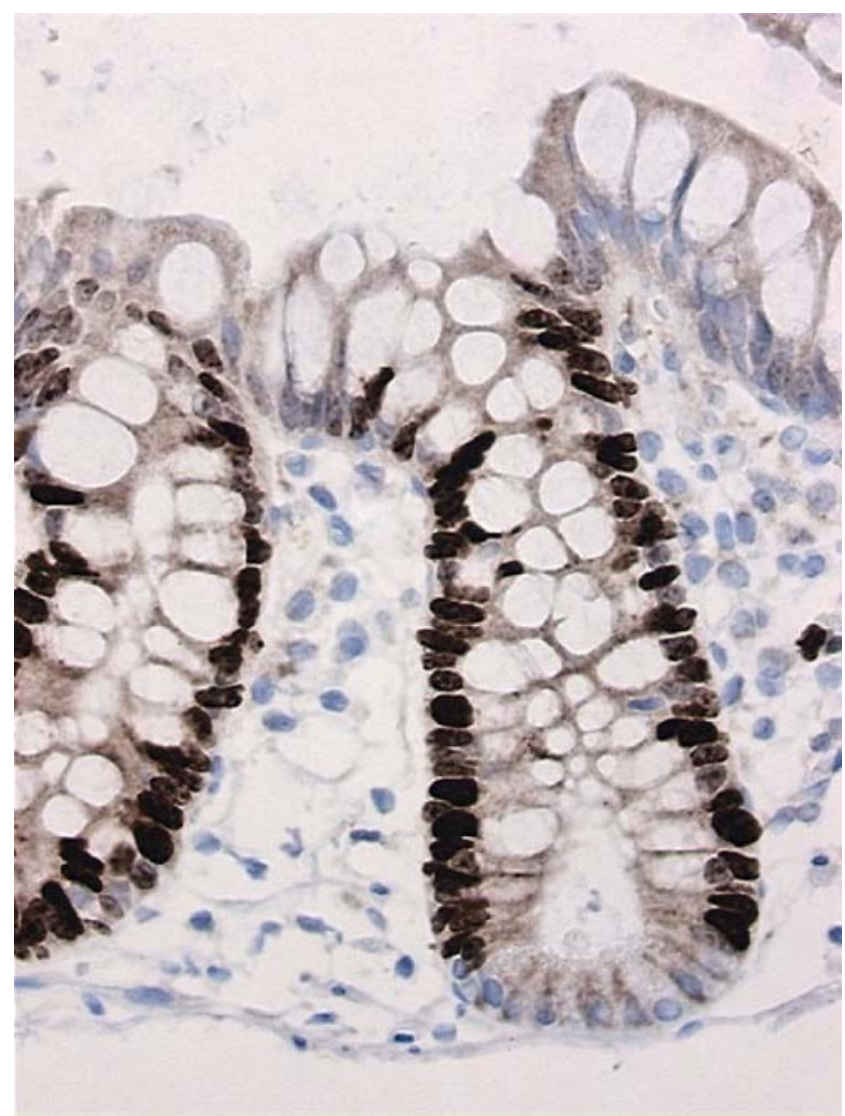

Fig. 3 Detection of proliferating crypt cells with MIB-1 immunohistochemistry. Brown stained nuclei are positive. Nonproliferative crypt stem cells are visualized at the base of the crypt. Original magnification $\times 400$

semiquantitative analyses showed more proliferation in the pouch $(n=11)$, this was confirmed by the quantitative method; the median value of the difference in proliferation between pouch and ileum was 0.107 (range 0.032-0.175). In the five cases where no difference was observed with the semiquantitative approach, the median value of the difference in proliferation between pouch and ileum was 0.023 (range -0.096 to 0.120 ). There were only three cases in which the semiquantitative method showed more proliferation in the afferent loop, and the median value of the difference in proliferation between pouch and ileum in these cases was 0.098 (range -0.021 to 0.262 ). The Spearman's correlation coefficient between the semiquantitative and the quantitative methods was $0.273(p=0.244)$.

\section{Discussion}

Although both the pouch and its afferent loop contain the same preexisting ileal mucosa, adenomas occur more frequently in the pouch of patients with FAP than in the afferent ileal loop, suggesting an accelerated adenoma formation in the pouch $[14,26,33,38]$. To investigate the 


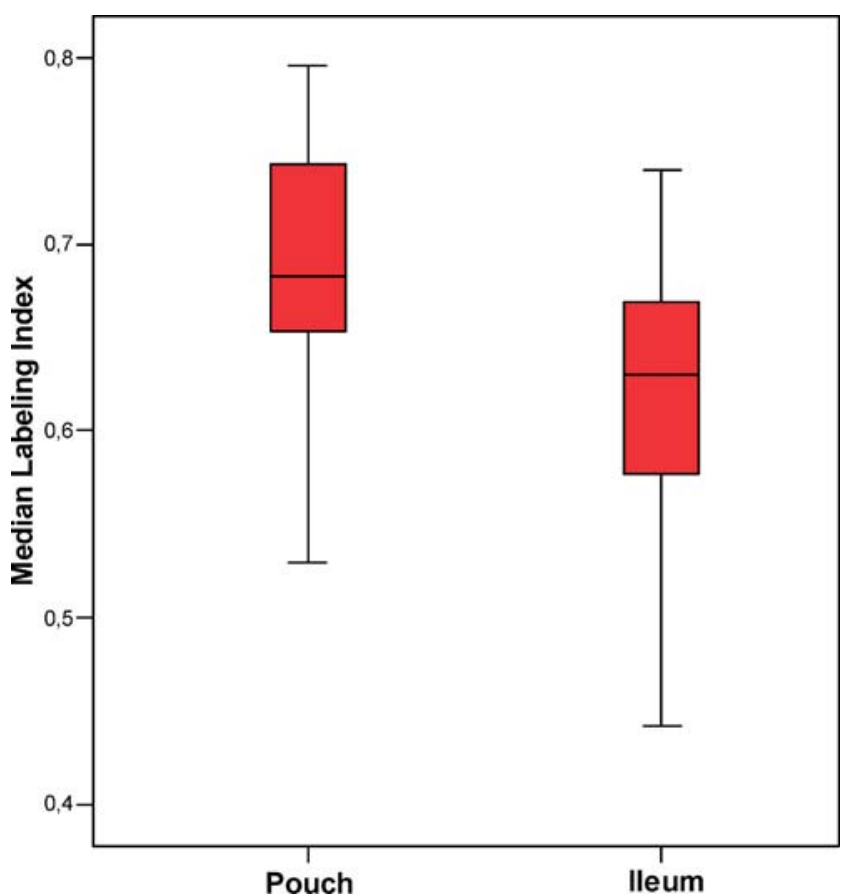

Fig. 4 Box-Whisker plots of cell proliferation expressed as median labeling index (MIB-1-positive crypt cells per total number of crypt cells) of 3-5 crypts in tissue sections of pouch and afferent ileum of 20 patients with FAP. Difference between groups was significant ( $p=$ 0.001). Values are given as median (fat line), lower to upper quartile (red box), and minimum and maximum values (error bars)

role of cell kinetics as a possible explanation for this observation, apoptosis and cell proliferation rates in the mucosa of the pouch were compared with those of the afferent ileal loop from the same patient to eliminate bias caused by interindividual differences. Cell proliferation was significantly higher in the pouch mucosa in comparison to mucosa of the afferent ileal loop. No significant difference in apoptosis was found in the mucosa of the pouch and afferent ileal loop.

A low amount of apoptotic cells in the pouch as well as in the ileal mucosa was found. This might be caused by the APC mutation-induced apoptotic resistance [16]. Only a trend but no significant difference in apoptosis was found. Taking into account the broad range of apoptotic rates as

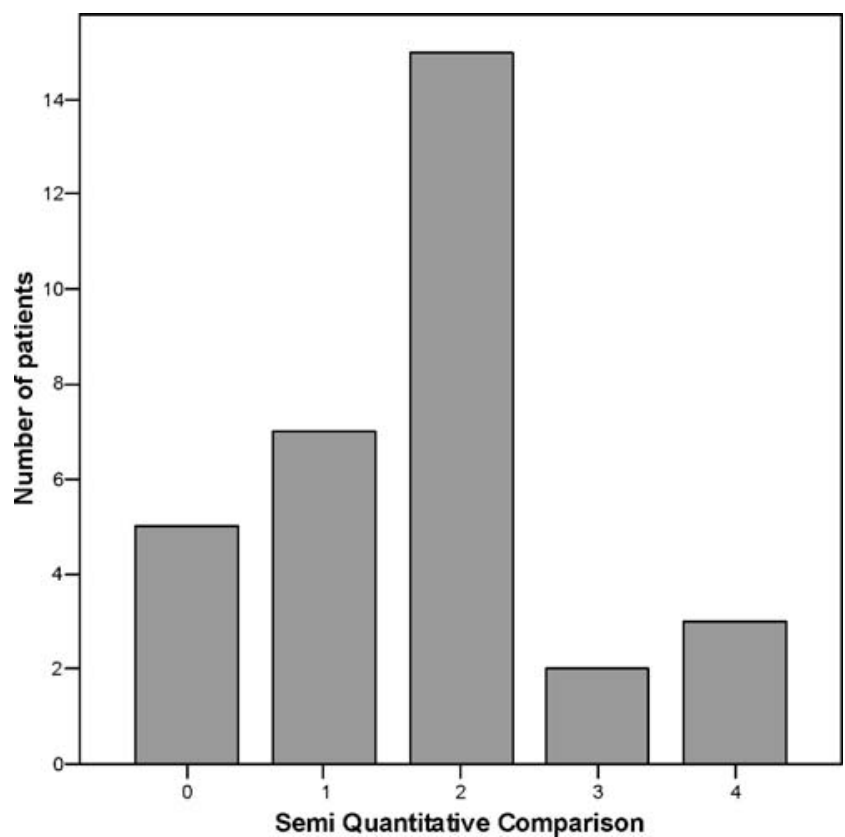

Fig. 6 Histogram of semiquantitative comparison; 0 ileal mucosa shows more cell proliferation than pouch mucosa, 1 no difference in cell proliferation between pouch and ileal mucosae, 2 pouch mucosa shows more cell proliferation than ileal mucosa, 3 no judgement possible, 4 no consensus could be reached

found in our study samples, a significant difference might be found when a larger group of patients could be studied. There are no clear guidelines for estimation of ileal proliferation. For estimation of colonic proliferation, an accepted method is to count proliferating cells in five colonic crypts. Although most biopsy specimens were stretched and orientated directly after endoscopy, only a lower number of crypts could be counted completely along the longitudinal axis in most patients. For this reason, we accepted three full crypts as the minimal number to assess proliferation. Using this criterion, tissue sections from 12 patients still could not be used to determine the cell proliferation and had to be excluded from the study. Especially in the tissue sections of the pouch, this problem was evident and is possibly caused by a higher fragility of this tissue. In the remaining 20 pairs of tissue sections left

Fig. 5 Photographs used for semiquantitative comparison of cell proliferation in MIB-1 immunohistochemically stained tissue sections of pouch (left) and afferent ileal mucosae (right; original magnification $\times 100$ )
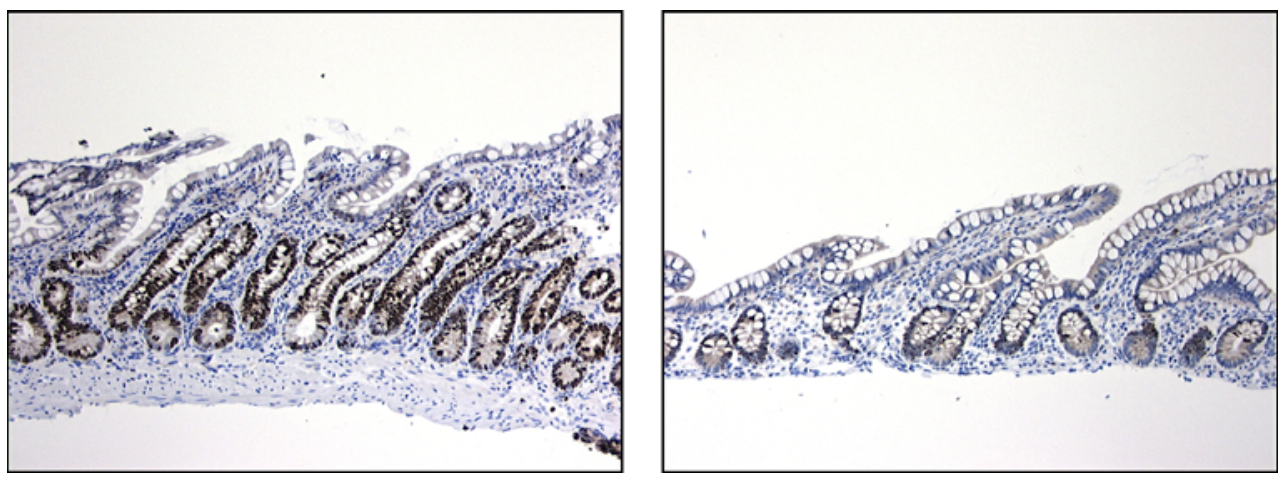


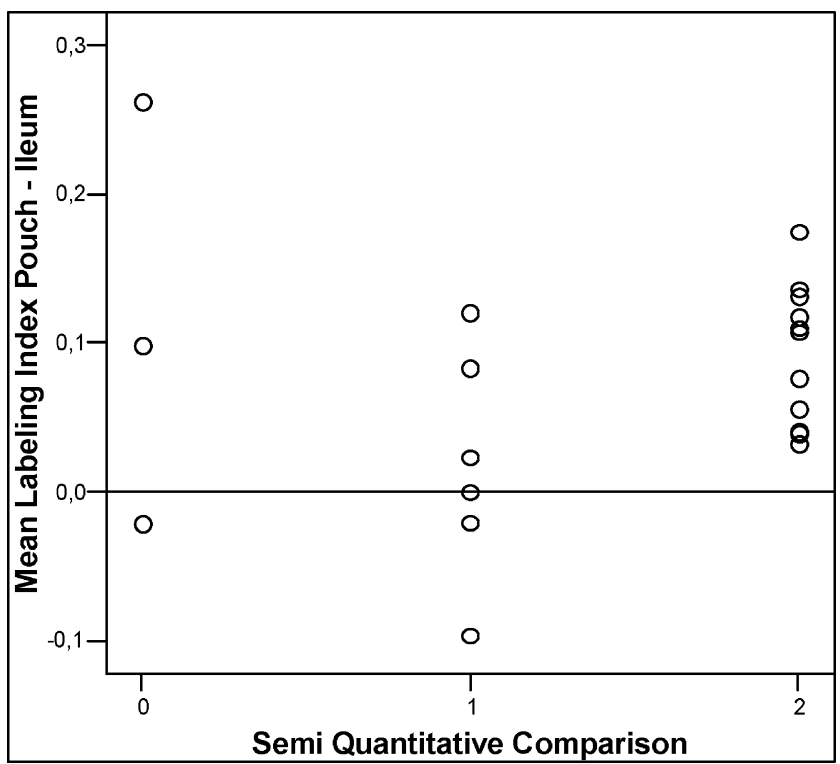

Fig. 7 Semiquantitative comparison vs difference in mean labeling index of pouch minus afferent ileal mucosa; 0 ileal mucosa shows more cell proliferation compared to the pouch mucosa, 1 no difference in cell proliferation between pouch and ileal mucosae, 2 pouch mucosa shows more cell proliferation compared to the ileal mucosa

for comparison, we found a significantly higher median labeling index in the pouch compared to the ileal afferent loop.

To overcome the problem of the relative low number of assessable crypts, another quicker but less quantitative method was applied in which five investigators compared photographs of tissue sections of pouch and ileal mucosae. In accordance with the results of the first method, we found significantly higher cell proliferation in the mucosa of the pouch compared to that of the ileal mucosa. Although no significant correlation could be found in a case-by-case comparison between both methods, in all cases in which the semiquantitative analyses showed more proliferation in the pouch, this was confirmed by the quantitative analyses of crypts. Furthermore, the inter- and intraobserver variability was good.

In addition, the semiquantitative method is far less timeconsuming and can therefore give a relatively fast and easy impression of eventual differences in cell proliferation. Evaluation of this method in a larger study may further demonstrate its value.

Data on cell proliferation in ileal mucosa in patients with FAP are limited. Previously, de Silva et al. [11] reported a labeling index of $19.8 \%$ in afferent ileal loop mucosa of patients with FAP or ulcerative colitis (UC), far lower than the $61.6 \%$ that was found here. Their labeling index for cell proliferation in ileal pouch mucosa $(33.6 \%)$ was also much lower than in the present study. Only the labeling index of $51.7 \%$ as found by them in pouches with pouchitis nears the values we obtained. However, the majority of patients included in the study of de Silva et al. were patients with UC (23 of the 26 patients), so direct comparison with our results therefore seems inappropriate. In addition, Goldberg et al. [12] reported a median labeling index of $34.9 \%$ in the ileal pouch of patients with FAP, which is much lower than the $68.3 \%$ we found. However, their labeling indices were based on a minimum of three counted crypts, and if this number could not be reached, halves of crypts were included in the analyses. Moreover, their study group consisted of only 5 patients with FAP, whereas in the present study, 3 to 5 whole crypts of 20 patients were counted.

Several studies indicated that cell proliferation of normal-appearing colorectal mucosa of patients with adenomas or carcinomas was 19 to $86 \%$ higher compared to colorectal mucosa of healthy persons $[1,28,30,32]$. These findings strongly suggest an association between the presence of adenomas or carcinomas and an increased mucosal cell proliferation. However, the difference in cell proliferation between pouch and afferent ileal mucosae of $6.7 \%$ as found in this study is less pronounced in comparison to the above referred findings. A possible explanation for this relatively small difference in cell proliferation between pouch and ileal mucosae in our study may be that intestinal epithelial cell proliferation is already very high in patients with FAP [19, 31], and these high cell proliferation rates make a further increase less pronounced.

The higher proliferation found in the pouch mucosa in comparison to mucosa of the afferent ileal loop can only be explained by intraluminal changes that occur after construction of the pouch. Whether changes in bacterial flora, bile acid composition, short-chain fatty acids, or other compounds are responsible for this finding remains unclear, but a better understanding of this process is necessary to find a possible treatment for this group of patients.

In conclusion, the increased cell proliferation in the ileal pouch mucosa compared to the mucosa of the afferent ileal loop may contribute to the enhanced risk for adenomas and carcinomas in the pouch of patients with FAP and emphasizes the need for regular endoscopical surveillance of the pouch in these patients. In addition, cell proliferation can be used as an early endpoint marker in chemopreventive studies in these patients.

The applied new method for semiquantitative evaluation of cell proliferation in immunohistochemically stained tissue sections seems promising, as it offers a relatively fast and easy means of assessment.

Acknowledgment This paper was made possible by a grant from the Dutch Cancer Society KUN 2003-2911. 


\section{References}

1. Anti M, Armuzzi A, Morini S, Iascone E, Pignataro G, Coco C, Lorenzetti R, Paolucci M, Covino M, Gasbarrini A, Vecchio F, Gasbarrini G (2001) Severe imbalance of cell proliferation and apoptosis in the left colon and in the rectosigmoid tract in subjects with a history of large adenomas. Gut 48:238-246

2. Bassuini MM, Billings PJ (1996) Carcinoma in an ileoanal pouch after restorative proctocolectomy for familial adenomatous polyposis. Br J Surg 83:506

3. Brown SR, Donati D, Seow-Choen F (2001) Rectal cancer after mucosectomy for ileoanal pouch in familial adenomatous polyposis: report of a case. Dis Colon Rectum 44:1714-1715

4. Bulow S, Bjork J, Christensen IJ, Fausa O, Jarvinen $\mathrm{H}$, Moesgaard F, Vasen HF (2004) Duodenal adenomatosis in familial adenomatous polyposis. Gut 53:381-386

5. Bussey HJ, Veale AM, Morson BC (1978) Genetics of gastrointestinal polyposis. Gastroenterology 74:1325-1330

6. Byrt T (1996) How good is that agreement? Epidemiology 7:561

7. Campos FG, Habr-Gama A, Kiss DR, da Silva EV, Rawet V, Imperiale AR, Perez R, da Silva JH, Sousa AH Jr, Gama-Rodrigues J (2005) Adenocarcinoma after ileoanal anastomosis for familial adenomatous polyposis: review of risk factors and current surveillance apropos of a case. J Gastrointest Surg 9:695-702

8. Cattoretti G, Becker MH, Key G, Duchrow M, Schluter C, Galle J, Gerdes J (1992) Monoclonal antibodies against recombinant parts of the Ki-67 antigen (MIB 1 and MIB 3) detect proliferating cells in microwave-processed formalinfixed paraffin sections. J Pathol 168:357-363

9. Cherki S, Glehen O, Moutardier V, Francois Y, Gilly FN, Vignal J (2003) Pouch adenocarcinoma after restorative proctocolectomy for familial adenomatous polyposis. Colorectal Dis 5:592-594

10. Clausen MR, Tvede M, Mortensen PB (1992) Short-chain fatty acids in pouch contents from patients with and without pouchitis after ileal pouch-anal anastomosis. Gastroenterology 103:1144-1153

11. de Silva HJ, Gatter KC, Millard PR, Kettlewell M, Mortensen NJ, Jewell DP (1990) Crypt cell proliferation and HLA-DR expression in pelvic ileal pouches. J Clin Pathol 43:824-828

12. Goldberg PA, Herbst F, Beckett CG, Martelli B, Kontakou M, Talbot IC, Ciclitira PJ, Nicholls RJ (1996) Leucocyte typing, cytokine expression, and epithelial turnover in the ileal pouch in patients with ulcerative colitis and familial adenomatous polyposis. Gut 38:549-553

13. Hoehner JC, Metcalf AM (1994) Development of invasive adenocarcinoma following colectomy with ileoanal anastomosis for familial polyposis coli. Report of a case. Dis Colon Rectum 37:824-828

14. Iida M, Itoh H, Matsui T, Mibu R, Iwashita A, Fujishima M (1989) Ileal adenomas in postcolectomy patients with familial adenomatosis coli/Gardner's syndrome. Incidence and endoscopic appearance. Dis Colon Rectum 32:1034-1038

15. Keller JJ, Offerhaus GJ, Polak M et al (1999) Rectal epithelial apoptosis in familial adenomatous polyposis patients treated with sulindac. Gut 45:822-828

16. Kim PJ, Plescia J, Clevers H, Fearon ER, Altieri DC (2003) Survivin and molecular pathogenesis of colorectal cancer. Lancet 362:205-209

17. Knasmuller S, Steinkellner H, Hirschl AM, Rabot S, Nobis EC, Kassie F (2001) Impact of bacteria in dairy products and of the intestinal microflora on the genotoxic and carcinogenic effects of heterocyclic aromatic amines. Mutat Res 480-481:129-138

18. Leers MP, Kolgen W, Bjorklund V, Bergman T, Tribbick G, Persson B, Bjorklund P, Ramaekers FC, Bjorklund B, Nap M, Jornvall H, Schutte B (1999) Immunocytochemical detection and mapping of a cytokeratin 18 neo-epitope exposed during early apoptosis. J Pathol 187:567-572

19. Mills SJ, Mathers JC, Chapman PD, Burn J, Gunn A (2001) Colonic crypt cell proliferation state assessed by whole crypt microdissection in sporadic neoplasia and familial adenomatous polyposis. Gut 48:41-46

20. Nasmyth DG, Godwin PG, Dixon MF, Williams NS, Johnston D (1989) Ileal ecology after pouch-anal anastomosis or ileostomy. A study of mucosal morphology, fecal bacteriology, fecal volatile fatty acids, and their interrelationship. Gastroenterology 96:817824

21. Natori H, Utsunomiya J, Yamamura T, Benno Y, Uchida K (1992) Fecal and stomal bile acid composition after ileostomy or ileoanal anastomosis in patients with chronic ulcerative colitis and adenomatosis coli. Gastroenterology 102:1278-1288

22. Newman JV, Kosaka T, Sheppard BJ, Fox JG, Schauer DB (2001) Bacterial infection promotes colon tumorigenesis in $\mathrm{Apc}(\mathrm{Min} /+)$ mice. J Infect Dis 184:227-230

23. Nugent KP, Spigelman AD, Nicholls RJ, Talbot IC, Neale K, Phillips RK (1993) Pouch adenomas in patients with familial adenomatous polyposis. Br J Surg 80:1620

24. Ooi BS, Remzi FH, Gramlich T, Church JM, Preen M, Fazio VW (2003) Anal transitional zone cancer after restorative proctocolectomy and ileoanal anastomosis in familial adenomatous polyposis: report of two cases. Dis Colon Rectum 46:1418-1423

25. Palkar VM, deSouza LJ, Jagannath P, Naresh KN (1997) Adenocarcinoma arising in "J" pouch after total proctocolectomy for familial polyposis coli. Indian J Cancer 34:16-19

26. Parc YR, Olschwang S, Desaint B, Schmitt G, Parc RG, Tiret E (2001) Familial adenomatous polyposis: prevalence of adenomas in the ileal pouch after restorative proctocolectomy. Ann Surg 233:360-364

27. Pasricha PJ, Bedi A, O'Connor K, Rashid A, Akhtar AJ, Zahurak ML, Piantadosi S, Hamilton SR, Giardiello FM (1995) The effects of sulindac on colorectal proliferation and apoptosis in familial adenomatous polyposis. Gastroenterology 109:994-998

28. Ponz de Leon M, Roncucci L, Di Donato P, Tassi L, Smerieri O, Amorico MG, Malagoli G, De Maria D, Antonioli A, Chahin NJ (1988) Pattern of epithelial cell proliferation in colorectal mucosa of normal subjects and of patients with adenomatous polyps or cancer of the large bowel. Cancer Res 48:4121-4126

29. Remzi FH, Church JM, Bast J, Lavery IC, Strong SA, Hull TL, Harris GJ, Delaney CP, O’Riordain MG, McGannon EA, Fazio VW (2001) Mucosectomy vs. stapled ileal pouch-anal anastomosis in patients with familial adenomatous polyposis: functional outcome and neoplasia control. Dis Colon Rectum 44:1590-1596

30. Risio M, Lipkin M, Candelaresi G, Bertone A, Coverlizza S, Rossini FP (1991) Correlations between rectal mucosa cell proliferation and the clinical and pathological features of nonfamilial neoplasia of the large intestine. Cancer Res 51:1917-1921

31. Santucci R, Volpe L, Zannoni U, Paganelli GM, Poggi B, Calabrese C, Biasco G (1997) Cell proliferation of the duodenal mucosa in patients affected by familial adenomatous polyposis. Gastroenterology 113:1159-1162

32. Terpstra OT, van Blankenstein M, Dees J, Eilers GA (1987) Abnormal pattern of cell proliferation in the entire colonic mucosa of patients with colon adenoma or cancer. Gastroenterology 92:704-708

33. Thompson-Fawcett MW, Marcus VA, Redston M, Cohen Z, McLeod RS (2001) Adenomatous polyps develop commonly in the ileal pouch of patients with familial adenomatous polyposis. Dis Colon Rectum 44:347-353 
34. Tonelli F, Nardi F, Bechi P, Taddei G, Gozzo P, Romagnoli P (1985) Extracolonic polyps in familial polyposis coli and Gardner's syndrome. Dis Colon Rectum 28:664-668

35. von Herbay A, Stern J, Herfarth C (1996) Pouch-anal cancer after restorative proctocolectomy for familial adenomatous polyposis. Am J Surg Pathol 20:995-999

36. Vrouenraets BC, van Duijvendijk P, Bemelman WA, Offerhaus GJ, Slors JF (2004) Adenocarcinoma in the anal canal after ileal pouch-anal anastomosis for familial adenomatous polyposis using a double-stapled technique: report of two cases. Dis Colon Rectum 47:530-534

37. Vuilleumier H, Halkic N, Ksontini R, Gillet M (2000) Columnar cuff cancer after restorative proctocolectomy for familial adenomatous polyposis. Gut 47:732-734

38. Wu JS, McGannon EA, Church JM (1998) Incidence of neoplastic polyps in the ileal pouch of patients with familial adenomatous polyposis after restorative proctocolectomy. Dis Colon Rectum $41: 552-556$ 